\title{
Insecticides Mode of Action in Relation to Their Toxicity to Non-Target Organisms
}

\section{Francisco Sánchez-Bayo*}

Centre for Ecotoxicology, University of Technology Sydney, Lidcombe NSW 2141, Australia

\begin{abstract}
The mode of action of insecticides is responsible for their higher or lower toxicity to non-target organisms. However, the large variations in susceptibility among different animal taxa indicate that certain biochemical traits particular to a group of organisms are responsible for a specific level of sensitivity. A review of toxicity data to non-target organisms is presented here. Aquatic arthropods are most susceptible to all types of insecticides because they share many physiological features with the target insects. Other aquatic organisms, such as fish and amphibians, are very sensitive to broad-spectrum neurotoxic and respiratory inhibitor insecticides, but not so much to selective insecticides such as IGRs and stomach poisons. Terrestrial vertebrates are also sensitive to most neuro-toxicants and respiratory inhibitors, with the exception of those insecticides derived from natural toxins produced by plants or fungi (e.g. pyrethroids, neonicotinoids, avermectins, spinosad), which appear to have little or no toxicity in birds and mammals.
\end{abstract}

Keywords: Review; Neurotoxicity; Inhibitors; Growth regulators

\section{Introduction}

The worldwide use of pesticides in agriculture results in residues of insecticides being commonly found in many environments, from the cropping fields and orchards to rivers, estuaries and oceans, and even urban environments $[1,2]$. Insecticides are useful to control pest outbreaks, but insecticide pollution is one of the many problems faced by our modern society. This is because the extreme toxicity of most of these natural and man-made chemicals affects not only the target pests but also many other species of animals, although in different degrees [3].

Indeed, insecticides can alter the ecological structure of earthworms and arthropod communities in the soil $[4,5]$ and around crops [6], thus affecting birds and other vertebrates that feed on these organisms [7]. Insecticide spray drift can kill birds in the vicinity of crops [8], and their water-borne residues can decimate zooplankton, aquatic larvae of crustaceans and insects for short or long periods of time $[9,10]$, or affect the growth and development of tadpoles [11] and fish [12].

It is imperative, therefore, that the society recognises the hazards and risks of using insecticides. Just because they are designed to kill insects, it does not exclude them from killing other animals, even humans $[13,14]$. We need to understand the toxic nature of these highly poisonous substances to the large variety of non-target organisms, so that precautionary measures may be taken to mitigate their negative effects in human health and the environment.

Many books and research articles have been published on the various mechanisms of pesticide toxicity, and insecticides in particular [15]. Unfortunately, in spite of all the technical knowledge gathered in this area of science in recent decades, little effort has been made to provide a comprehensive review on the toxicity levels of all kinds of insecticides to the various non-target taxa. An old review of this kind considered arthropods only [16], whereas more recent reviews have focused on sublethal effects on beneficial arthropods [17]. Toxicity data of individual compounds to certain species exists, but it is mainly found in the Pesticide Manual [18] and databases like ECOTOX of the US EPA (http://cfpub.epa.gov/ecotox/). However, raw data such as these have no meaning to the man on the street, not even to the educated person. Numbers by themselves cannot tell the story. What is needed is a readily available document that explains the hazards of the different insecticidal compounds and their comparative toxicity to non-target organisms, pinpointing the most toxic compounds in the market, so that people working with pesticides (mainly farmers and applicators, but also consultants, regulators, agronomists and environmentalists) may understand what they are dealing with. Only from such a perspective we will be able to grasp adequately any problem arising from insecticide usage.

This paper aims at closing that gap in knowledge. Insecticide effects on non-target organisms are discussed in relation to the specific mode of action of the compounds, in an attempt to clarify why certain insecticidal compounds are more toxic than others to specific taxa.

\section{Toxicity of Insecticides to Non-Target Organisms}

The potency of a toxic chemical is usually gauged by its lethal median dose (LD50), median lethal concentration (LC50) or median effective concentration (EC50) to surrogate species belonging to common taxa, i.e. fish, mammals, birds, crustaceans, worms and bees. With the exception of insect pests, which are the target of the insecticides, all other species and taxa are considered non-target organisms. It is a fact that different species within the same taxonomic class can vary considerably, e.g. one or two orders of magnitude, in susceptibility to a given toxicant, so selection of representative test species for the OECD standard testing protocols is important [19,20]. However, a comparison of $\mathrm{L}(\mathrm{D}) \mathrm{C} 50$ values for a range of insecticides tested on the same species provides a practical way of assessing the relative potency of such chemicals to the taxon they represent. Often a given insecticide has been tested on several species of the same taxonomic group, thus providing a range of $\mathrm{L}(\mathrm{D}) \mathrm{C} 50$ s for that taxon and, therefore, more

*Corresponding author: Francisco Sánchez-Bayo, Centre for Ecotoxicology, University of Technology Sydney, Lidcombe NSW 2141, Australia, E-mail: sanchezbayo@mac.com

Received December 06, 2011; Accepted January 13, 2012; Published January 16,2012

Citation: Sánchez-Bayo F (2012) Insecticides Mode of Action in Relation to Their Toxicity to Non-Target Organisms. J Environment Analytic Toxicol S4:002. doi:10.4172/2161-0525.S4-002

Copyright: (c) 2012 Sánchez-Bayo F. This is an open-access article distributed under the terms of the Creative Commons Attribution License, which permits unrestricted use, distribution, and reproduction in any medium, provided the original author and source are credited. 
certainty about the hazards posed by the insecticide to that particular group of non-target organisms.

This paper is a review of available L(D)C50 and EC50 data for currently used insecticides to main non-target animal taxa, not a review of literature on the subject. Acute toxicity data were obtained mostly from the ECOTOX database and the Pesticide Manual, complemented with other published material $[21,22]$. An analysis of such data was carried out with the aim of obtaining patterns of toxicity among groups of insecticides with different mode of action. It is hypothesised that chemicals with the same mode of action should have similar L(D)C50 or EC50 values for the representative surrogate species, their differences probably arising from the particular molecular structure and reactivity of each individual insecticide.

Based on these premises, the hazards posed by groups of insecticides with the same mode of action to main taxa can be expressed by a range of L(D)C50 values and the average value for all chemicals in that group, as explained in Sánchez-Bayo [22]. That average is calculated as the geometric mean of all the individual values for chemicals in the same groups, given that they typically follow a lognormal distribution [22]. With the only purpose of comparing the relative potency of insecticides belonging to such groups, their average values to the main non-target organisms are shown in table 1.

Organisms are affected by the toxicity of insecticides firstly upon direct exposure to these chemicals. The route of exposure is essential in determining the effects at the individual level. Thus, after spraying a field crop with an organo phosphorus (OP) insecticide, birds that receive the spray directly on the feathers may get more exposure and die sooner than those that simply inhale its vapour, or those that eat contaminated grain or insects [23]. Ingestion, on the other hand, may be a more crucial route of exposure in the case of organo chlorine (OC) insecticides because these are persistent and accumulate in the body, so the exposure route depends to a large extent on the chemistry of each compound.

When exposure to an insecticide is below its mortality levels, the individuals affected may undergo sublethal effects, which are unrelated to the specific mode of action of that insecticide. Sublethal effects are not considered in this paper, but it is worth mentioning some examples: the reproduction impairment as a consequence of sperm deformity in earthworms caused by imidacloprid [24], the depressed immunological response of frogs to trematode infections [25] and the disruption of endocrine regulatory systems in many organisms by a number of pesticides [26]. Sublethal effects are unpredictable so long as they are due to unknown physiological mechanisms. The best known sublethal mechanism is the thinning of eggshells in birds caused by accumulation of DDE and OC residues [27,28], which results in high frequency of eggs breaking and, therefore, in reproduction failure $[29,30]$. Behavioural changes are also sublethal effects even if they may result from the neurotoxic activity of the insecticide. For example, bees exposed to low doses of permethrin are not actively involved with foraging, but spend their time rubbing legs, trembling, dancing and in self-cleaning activities [31]. Frogs exposed to malathion have reduced predatory skills [32], and starlings exposed to OP insecticides neglect looking after their nestlings, thus causing early death of chicks and reproduction failure [33].

\section{How the Mode of Action Determines the Toxicity and Selectivity of Insecticides}

The toxicity and specificity of insecticides is a consequence of their biochemical mode of action at the cellular or physiological level in organisms. Whilst toxicity is determined by the internal dose required to cause the death of an organism (Paracelsus), the specificity depends on the biochemical or physiological mechanisms targeted by the insecticide, which can either vary substantially among taxa (i.e. selective insecticides) or be similar for all animals (i.e. broad-spectrum insecticides). Obviously, broad-spectrum insecticides are hazardous to all kinds of animals, even if their lethal doses are necessarily higher for larger animals than for small insects.

The following paragraphs contain a discussion on the toxic characteristics of each group of insecticides to non-target organisms based on their mechanism of action.

\section{Neurotoxic insecticides}

Their target is one of the five neurotransmitter systems - particularly cholinergic- found in the neuronal system of arthropods, which are either activated (agonist action) or inhibited (antagonist action) by the insecticide. Break down of the neuronal activity causes brain death or affects the motor system through paralysis, convulsions, hyperactivity and spasms. Organisms susceptible to this kind of poisons include all arthropods, vertebrates, earthworms and marine worms, molluscs and other organisms with a developed neuronal system.

Acetylcholinesterase (AChE) inhibitors comprise the organophosphorous (e.g. chlorpyrifos, dimethoate and 60 others) and carbamate (e.g. aldicarb, methomyl, pirimicarb and 25 others) insecticides. Since AChE is the main enzyme in the nicotine and muscarine receptors of neurons and muscular junctions in animals, they are broad-spectrum and very toxic poisons, especially to bees, mammals and birds (Table 1). Organophosphorous insecticides tend to be slightly more toxic than carbamates, in particular to aquatic organisms, and this may be due to the fact that their binding to the receptor is irreversible, whereas that of carbamates is not [15]. The only exception is the worms, for which LC50 values of carbamates are generally lower than those of OPs. For this reason, many carbamate products are used as nematicides and soil sterilants.

$\gamma$-aminobutyric acid receptors (GABA-R) are located in the postsynaptic dendrites of the central nervous system in all animals, but in arthropods also in the neuromuscular junctions and ganglia. The avermectins (e.g. abamectin) are agonists of these receptors [34], and are particularly toxic to all arthropods (i.e. crustaceans, bees and spiders) - in fact, they are the most toxic insecticides to bees and zooplankton cladocerans (Table 1). Less susceptibility of vertebrates, including fish, to avermectins may be indicative of a different type of GABA-R in higher animals. The organochlorine cyclodiene insecticides (e.g. endosulfan) are antagonists of GABA-R [35], and appear to be quite toxic to most animals, especially to fish and macro-crustaceans, and to large extent worms. Fipronil is also antagonist of this receptor [36], and is equally toxic to vertebrates but not to fish. Lack of toxicological information about this new insecticide prevents any assessment of its impacts on amphibians, worms and bees. Zooplankton cladocerans seem to be less susceptible to all GABA-R antagonists than to agonists.

Nicotine acetylcholinesterase receptors (nACh-R) are located in the post-synaptic dendrites of all neurons in the brain, spinal cord, ganglia, and muscular junctions. Nicotine, neonicotinoids (e.g. imidacloprid, thiacloprid) and spinosad activate it $[37,38]$ causing hyperactivity and death in insects and worms. Their extreme toxicity to insects contrasts with their low toxicity to all vertebrate taxa, and this selectivity is due to a different kind of $\mathrm{nACh}-\mathrm{R}$ found in vertebrates $[38,39]$. Although neonicotinoids are not toxic to Daphnia and cladocerans in general, they - and imidacloprid in particular - can be toxic to other crustaceans 
Citation: Sánchez-Bayo F (2012) Insecticides Mode of Action in Relation to Their Toxicity to Non-Target Organisms. J Environment Analytic Toxico S4:002. doi:10.4172/2161-0525.S4-002

Page 3 of 9

\begin{tabular}{|c|c|c|c|c|c|c|c|c|c|c|c|c|}
\hline \multirow{3}{*}{ Group } & \multirow{3}{*}{ Mode of action } & \multirow{3}{*}{ Insecticide class } & \multirow{3}{*}{$\mathrm{n}$} & \multicolumn{5}{|c|}{ Aquatic organisms } & \multicolumn{4}{|c|}{ Terrestrial organisms } \\
\hline & & & & Cladocerans & $\begin{array}{c}\text { Macro- } \\
\text { crustaceans }\end{array}$ & $\begin{array}{l}\text { Aquatic } \\
\text { insects }\end{array}$ & Fish & Amphibians & \multirow{2}{*}{$\begin{array}{c}\text { Bees } \\
\mu \mathrm{g} / \mathrm{bee}\end{array}$} & \multirow{2}{*}{\begin{tabular}{|c|} 
Earthworms \\
$\mathrm{mg} / \mathrm{kg}$ soil
\end{tabular}} & Birds & Mammals \\
\hline & & & & \multicolumn{3}{|c|}{$\mu g / L$} & \multicolumn{2}{|r|}{$\mathrm{mg} / \mathrm{L}$} & & & \multicolumn{2}{|c|}{$\mathrm{mg} / \mathrm{kg}$ body weight } \\
\hline \multirow{9}{*}{ Neurotoxic } & \multirow{2}{*}{ AChE (-) } & Carbamates & 28 & 88.5 & 385.7 & 259.1 & 4.9 & 17.0 & 0.71 & 76 & 49 & 98 \\
\hline & & Organophosphorus & 62 & 11.5 & 55.3 & 65.4 & 2.5 & 5.3 & 0.58 & 131 & 33 & 99 \\
\hline & \multirow[b]{2}{*}{$\begin{array}{r}\text { GABA-R (+) } \\
(-)\end{array}$} & Avermectins & 3 & 0.7 & 77.3 & - & 270.9 & - & 0.04 & 363 & 673 & 209 \\
\hline & & $\begin{array}{l}\text { Cyclodiene OC, } \\
\text { fipronil }\end{array}$ & 4 & $\begin{array}{r}328.7 \\
1995.0\end{array}$ & $\begin{array}{r}27.8 \\
-\end{array}$ & $\begin{array}{r}33.9 \\
-\end{array}$ & $\begin{array}{r}0.04 \\
254.3\end{array}$ & $\begin{array}{r}2.91 \\
-\end{array}$ & 2.24 & $\begin{array}{r}93 \\
-\end{array}$ & $\begin{array}{l}69 \\
39\end{array}$ & $\begin{array}{r}219 \\
96\end{array}$ \\
\hline & \multirow{2}{*}{$\begin{array}{r}\mathrm{nACh}-\mathrm{R}(+) \\
(-)\end{array}$} & Neonicotinoids, spinosad & 9 & 30441.0 & 4137 & 6.0 & 60.8 & 162.8 & 0.13 & 54 & 659 & 868 \\
\hline & & Dithiols & 4 & 11466.0 & - & - & 1.9 & 0.5 & 17.5 & - & 26 & 409 \\
\hline & \multirow{2}{*}{$\begin{array}{r}\text { Na channel }(+) \\
(-)\end{array}$} & Pyrethroids, DDT & 47 & 7.6 & 3.3 & 1.6 & 0.02 & 0.13 & 0.4 & 96 & 2521 & 826 \\
\hline & & Indoxacarb & 1 & 600.0 & - & - & 0.8 & - & 1.3 & 1250 & 98 & 1000 \\
\hline & Octopamine-R (-) & Amitraz & 1 & 35.0 & - & 24630.0 & 0.6 & 8.6 & 50.0 & 1000 & 788 & 1125 \\
\hline \multirow{3}{*}{$\begin{array}{l}\text { Respiration } \\
\text { inhibitors }\end{array}$} & ATPase (-) & $\begin{array}{l}\text { Organo-metallic, } \\
\text { propargite }\end{array}$ & 4 & 64.0 & 101.0 & 14800.0 & 0.2 & 0.1 & 1044.2 & 592 & 2631 & 1657 \\
\hline & $\mathrm{e}^{-}$transport (-) & Miscellaneous & 13 & 59.4 & 1943.0 & 796.3 & 0.3 & 0.9 & 3.9 & 91 & 642 & 923 \\
\hline & Other & Fumigants & 9 & 1477.3 & 144.0 & - & 1.5 & - & 25.0 & - & 95 & 118 \\
\hline \multirow{4}{*}{$\begin{array}{l}\text { Growth } \\
\text { inhibitors }\end{array}$} & Chitin (-) & $\begin{array}{l}\text { Benzoylureas, } \\
\text { cyromazine, buprofezin }\end{array}$ & 13 & 4.0 & 11.7 & 940.1 & 12.5 & 122.1 & 49.9 & 622 & 2287 & 3831 \\
\hline & Mite growth (-) & Miscellaneous & 5 & 395.1 & - & - & 12.8 & - & 90.3 & 1000 & 2675 & 2638 \\
\hline & \multirow{2}{*}{ Hormone mimics $(+)$} & Ecdysone agonists & 6 & 8435.0 & 16733.0 & 344.5 & 8.6 & 8.4 & 108.1 & 1044 & 2667 & 3832 \\
\hline & & Juvenile hormones & 5 & 227.6 & - & 92.0 & 1.5 & - & 9.3 & 850 & 3477 & 5743 \\
\hline $\begin{array}{l}\text { Stomach } \\
\text { poisons }\end{array}$ & Membrane disruption & $\begin{array}{l}\text { B. thuringiensis }(\mathrm{Bt}) \text {, } \\
\text { sulcofuron, cryolite }\end{array}$ & 3 & 9300.0 & - & - & 10.7 & - & - & - & 1779 & 2823 \\
\hline \multirow{2}{*}{ Others } & Detoxification (-) & Synergists & 4 & 17933.0 & - & 2740.0 & 9.8 & 2.1 & 49.0 & 330 & 4329 & 3272 \\
\hline & Lures & Pheromones & 36 & 2872.0 & 10000.0 & - & 25.7 & - & - & - & 3160 & 4999 \\
\hline
\end{tabular}

*Geometric mean oral LD50s (bees, birds, mammals) or LC50s (aquatic, worms) for all compounds (n) in a class. Dash denotes no data available. Sources: ECOTOX (http://cfpub.epa.gov/ecotox/), [18, 21, 22]

${ }^{1}$ Chemicals that are not produced anymore or have been banned from usage are not included here

Table 1: Comparative toxicity* of insecticides to non-target organisms, according to their mode of action: agonists (+) and antagonists (-) to specified receptors.

[40]. The dithiols (e.g. cartap) are antagonists of the nACh-R [18], which they block causing paralysis and eventually death. In contrast to the agonists, the nACh-R antagonists are very toxic to birds and amphibians but not so much to bees.

Sodium channels are located in all neuronal membranes. In arthropods, fish and other aquatic animals, these channels are kept open by DDT and methoxychlor, pyrethrins and synthetic pyrethroids (e.g. deltamethrin and 45 others), thus causing loss of nervous impulse (knockdown) and eventually death. Pyrethroids and other agonists of the sodium channels are the most toxic insecticides affecting aquatic organisms, in particular fish and crustaceans (Table 1), but are practically harmless to terrestrial vertebrates [41]. Indoxacarb acts as antagonist [18], blocking the sodium channels: it is also very toxic to fish and birds, whereas is less toxic to other vertebrates.

Octapomine receptors: amitraz inhibits the octopamine receptors involved in energy demanding activities in invertebrates (e.g. jumping, flying, light emission, etc), which are modulated by the dopaminergic system. Amitraz is quite toxic to zooplankton cladocerans and perhaps other crustaceans (no data available). In vertebrates this receptor is associated with noradrenalinergic systems; so with the exception of fish, amitraz is not very toxic to vertebrate taxa [42].

\section{Respiration inhibitors}

All compounds with this mode of action are broad-spectrum insecticides, since they disrupt the mitochondrial oxidative phosphorylation system common to most animals. However, depending on the biochemical pathway they affect, their toxicity can vary widely among taxa.
ATPase inhibitors such as the organotins and propargite, which are used as acaricides, are particularly toxic to all aquatic organisms, from crustaceans to fish and amphibians. However, they seem to be relatively harmless to bees and terrestrial vertebrates, suggesting that the sophisticated detoxification mechanisms found in terrestrial animals mitigate the action of these highly toxic substances in the latter taxa [43].

Disrupters of the electron transport mechanism in the mitochondria include those that uncouple complex I (e.g. rotenone), complex II (e.g. dicofol) or complex III (e.g. acequinocyl). However, for most compounds in this class (e.g. chlorfenapyr, diafenthiuron, DNOC, etc.) the exact target is unknown. In any case, they are very toxic to fish, amphibians, zooplankton and worms, but less toxic to vertebrates, except for chlorfenapyr, which is very toxic to birds [44].

The specific mechanisms of fumigant toxicity are not known, but these chemicals are very toxic to birds and mammals (Table 1). Hazards are likely to be enhanced among these organisms because of their direct exposure through inhalation of the volatile fumigants. Aquatic organisms, by contrast, are less susceptible to these compounds [45].

\section{Growth inhibitors and regulators (IGR)}

These are selective insecticides that break the life-cycle of arthropod development and metamorphosis. Consequently, they are quite harmless to all vertebrates and non-arthropod invertebrates such as worms, molluscs, etc.

Inhibitors of chitin biosynthesis include the benzoylureas (e.g. diflubenzuron), cyromazine and buprofezin, which disrupt growth in 
all arthropods, since they all have an exoskeleton made of chitin [46]. For the same reason, all crustaceans are very susceptible (Table 1), and can be seriously affected when exposed to residues of these compounds in waters $[47,48]$.

Mite growth disruptors (e.g. clofentezine) are selective to this taxon, and practically non-toxic for all other animals except crustaceans, which are moderately susceptible. The specific mechanisms of action differ among compounds, and in most cases are unknown [18].

Ecdysone agonists. The steroidal hormone ecdysone, which prompts moulting in arthropods, is mimicked by azadirachtin and diacylhydrazines (e.g. tebufenozide). These compounds are agonists that cause premature moulting in the larval stages of some insect taxa such as Lepidoptera -but not bees-, thus preventing them from reaching the adult stage in due time [49]. Very selective and nonhazardous insecticides to any other animal taxa [50].

Juvenile hormone analogues $(\mathrm{JH})$. Methoprene, hydroprene, kinoprene, pyriproxyfen and fenoxycarb act also as agonists of the hormonal system that keeps all insects (including bees) in their larvae stage, thus preventing the pupae to moult into adults [51]. Although they are selective insecticides, can also affect zooplankton cladocerans [52], suggesting they also mimic the hormones involved in the moulting of crustaceans.

\section{Stomach poisons}

Cryolite, sulcofuron sodium and the Cry toxins produced by Bacillus thuringiensis $(\mathrm{Bt})$ destroy the midgut tissues in caterpillars [53], being therefore very specific to Lepidoptera insects but quite harmless to all other insects and animal taxa.

\section{Other modes of action}

Pymetrozine and azadirachtin have anti-feedant properties [54, 55], but the mechanism involved in this action is not well understood. Synergists (e.g. piperonyl butoxide) enhance the toxicity of other insecticides by inhibiting the cellular detoxification mechanisms (e.g. monoxygenases, cytochrome P450, etc) [56], and can be toxic by themselves. Natural or artificial pheromones attract individuals of the same pest species (i.e. sex pheromones for females), being the most specific substances used in insect control [57] and probably the safest for non-target organisms (Table 1).

\section{Comparative Toxicity of Insecticides to Animal Taxa}

Unlike entomologists, who are concerned with the efficacy of individual insecticides to target pests, ecotoxicologists are more interested in the negative effects that such substances may have on the large array of organisms found in natural ecosystems. The information presented above gives an idea of the physiological effects that animals may undergo when exposed to different kinds of insecticides. Such an understanding is important but insufficient to evaluate the possible effects of insecticides in animal populations. Indeed, ecotoxicologists and regulators would like to know what insecticide classes are most dangerous to certain species or taxonomic groups. A comparison of the acute toxicity of each class of insecticides provides in part an answer to that question. The full answer, however, requires additional information on the effects these chemicals may have within communities, since species do not live in isolation but interact with other species. However, this is beyond the scope of this paper.

An analysis of the acute toxicity data of insecticides to common surrogate species of the main animal taxa, enables us to compare the hazards of each class of insecticides to such taxonomic groups. A range of acute toxicity values for all compounds with the same mode of action is shown in figure 1 (LC50 for aquatic organisms) and figure 2 (LD50 for terrestrial organisms), indicating the maximum and minimum values as well as the most common range for $50 \%$ of the compounds (between the 25 and 75 percentiles), which can be considered the typical L(C) D50 range for the insecticide class.

The insecticide classes in figures 1 and 2 refer to groups of compounds with the same mode of action. Only compounds for which this is unknown, e.g. pentachlorophenol (PCP), have been excluded. One can expect that toxicity of newly developed insecticides will fall within the range of the particular class they belong to.

\section{Aquatic organisms}

The susceptibility of aquatic organisms to most insecticides is due not only to sharing the same neurological and respiratory mechanisms as insects but also to lacking proper detoxification systems. This is because aquatic organisms are old in an evolutionary sense, and their primitive isoenzymes of cytochrome $\mathrm{P} 450$ and monoxygenases are somehow inefficient, so these organisms are unable to degrade most toxic compounds that enter their bodies [58]. By contrast, terrestrial organisms have developed more efficient isoenzymes and are better endowed to cope with the plethora of toxic substances found in their environment [Figure 1a-d]

Cladocerans: Zooplankton cladocerans are very sensitive to neurotoxic insecticides, particularly to avermectins (LC50 range 0.34 $1.0 \mu \mathrm{g} / \mathrm{L}$ ), pyrethroids (typical LC50 0.33-40 $\mu \mathrm{g} / \mathrm{L}$ ), OP cholinesterase inhibitors (typical LC50 1.7-65 $\mu \mathrm{g} / \mathrm{L}$ ) and amitraz (LC50 $35 \mu \mathrm{g} / \mathrm{L}$ ), as well as to chitin inhibitors. Among the latter compounds, flufenoxuron and hexaflumuron are particularly toxic to cladocerans, with LC50s of 0.04 and $0.1 \mu \mathrm{g} / \mathrm{L}$ respectively; however, large differences in toxicity among the pyrethroids, OPs and chitin inhibitors are obvious, reflecting the variety of existing compounds within the same class (Figure 1a). While these five classes of insecticides are the most hazardous to zooplankton crustaceans, other neurotoxic substances such as carbamates, OC insecticides and indoxacarb, as well as all respiratory inhibitors are also quite toxic to these organisms, with LC50s usually in the range 60-600 $\mu \mathrm{g} / \mathrm{L}$. Equally toxic are the JHs, with LC50s in the range 110-400 $\mu \mathrm{g} / \mathrm{L}$.

With the exception of the chitin inhibitors and JHs, cladoceran crustaceans are very tolerant of all other IGRs, which typically have LC50s above $1 \mathrm{mg} / \mathrm{L}$. Agonists and antagonists of the nicotinic receptor (nACh-R) such as neonicotinoids, dithiols and spinosad are the least toxic insecticides to these plank tonic organisms (typical LC50 10-120 $\mathrm{mg} / \mathrm{L})$.

Because of their high sensitivity to most insecticides, testing of cladocerans is internationally recognised as representative of the hazards that toxic chemicals pose to zooplankton organisms [59]. However, other plank tonic crustaceans can differ in susceptibility to some insecticide classes. For example, carbamate and OC insecticides are significantly more toxic to copepods and ostracods than to cladocerans, and copepods and brine shrimps are more susceptible to organo metallic compounds than cladocerans and ostracods [22]. In this regard, it should be noticed that imidacloprid can be quite toxic to epibenthic crustaceans such as freshwater ostracods, with LC50s two orders of magnitude lower (range 300-700 $\mu \mathrm{g} / \mathrm{L}$ ) than those for cladocerans [40].

Macro-crustaceans: Macro-crustaceans such as amphipods, mysids and decapods vary in sensitivity with respect to cladocerans. 


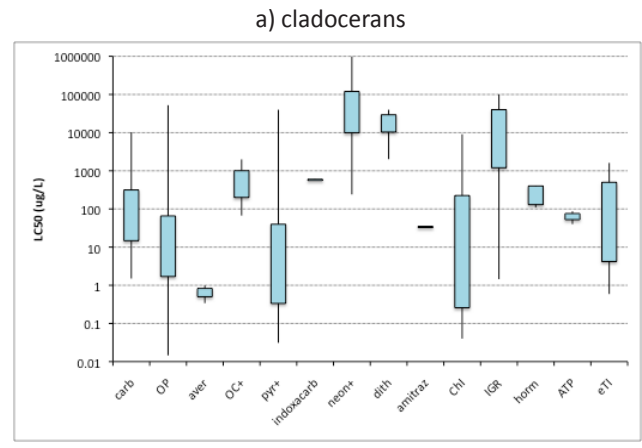

c)aquatic insects

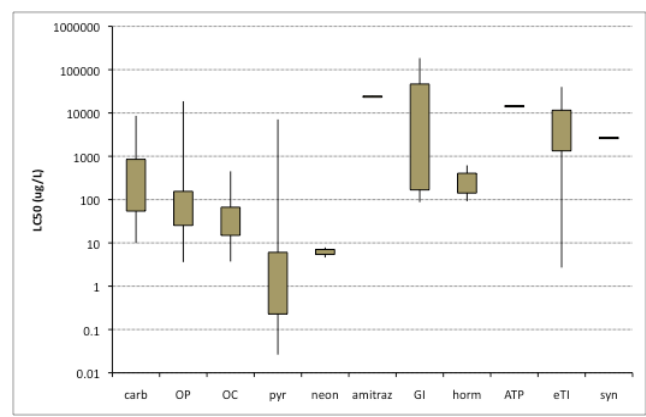

e) amphibians

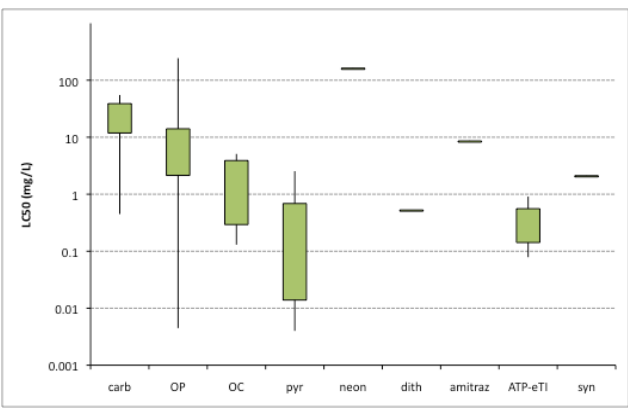

b) macro-crustaceans

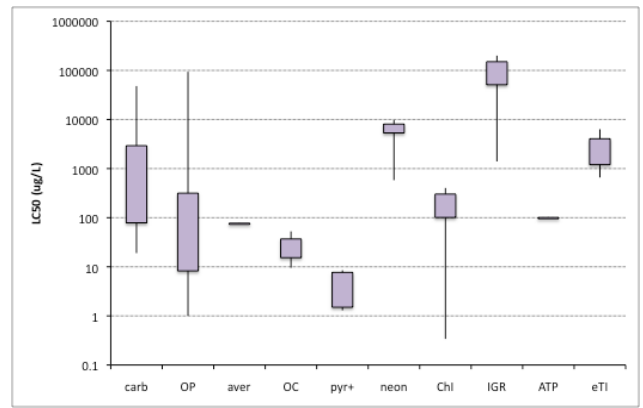

d) fish

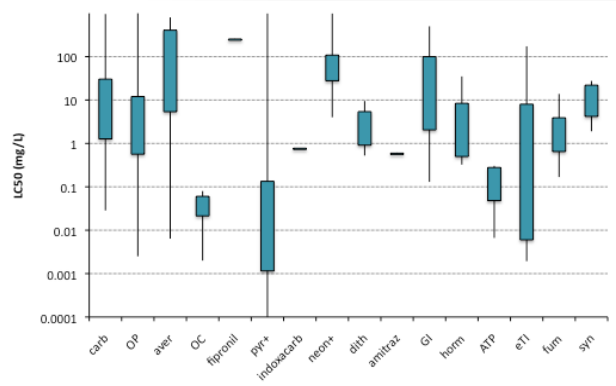

Figure 1: Abbreviations for the insecticide classes: carb = carbamates; OP = organophosphates; aver = avermectins; OC+ = organochlorines + fipronil; pyr+ = pyrethroids + DDT; neon+ = neonicotinoids + spinosad; Chl = chitin inhibitors; GI = growth inhibitors; IGR = insect growth regulators; horm = hormone mimics; dith = dithiols; ATP = ATPase inhibitors; eTI = electron transport inhibitors; fum = fumigants; syn = synergists

Regardless of the size difference, OC insecticides are about one order of magnitude more toxic to non-planktonic crustaceans (typical LC50 15-37 $\mu \mathrm{g} / \mathrm{L}$ ), while pyrethroids and OPs continue to be the most toxic insecticides to large crustaceans, with LC50s for 50\% of their compounds in the range 1.5-7.7 and 8-316 $\mu \mathrm{g} / \mathrm{L}$, respectively (Figure 1b). Also, while carbamates and chitin inhibitors have similar toxicity as in cladocerans, avermectins are not as toxic to macro-crustaceans (e.g. abamectin LC50 $77 \mu \mathrm{g} / \mathrm{L}$, [18]).

It is also interesting to note that most respiratory inhibitors -except for propargite- show little toxicity in large crustaceans (typical LC50 1.2-4.0 mg/L). In contrast, neonicotinoids and spinosad are one order of magnitude more toxic to macro-crustaceans than to cladocerans, with LC50s for $50 \%$ of their compounds in the range 5.3-8.0 mg/L, although these are not very toxic levels.

Aquatic insects: Toxicity levels of insecticides for non-target aquatic insects do not differ much from those of crustaceans, with neurotoxic compounds being more toxic than others. As it could be expected, pyrethroids are the most toxic insecticides to larvae of mayflies, caddisflies, stoneflies, dragonflies and aquatic beetles (typical L50 1.6 $\mu \mathrm{g} / \mathrm{L}$ ), followed by neonicotinoids (typical L50 $6.0 \mu \mathrm{g} / \mathrm{L}$ ), although information for this class of compounds is still scarce. Aquatic insects appear to be more sensitive to OC insecticides than to cholinesterase inhibitors, with OPs being more toxic than carbamates: typical LC50 values are in the range 15-67 $\mu \mathrm{g} / \mathrm{L}$ for OCs, $25-155 \mu \mathrm{g} / \mathrm{L}$ for OPs and 54$850 \mu \mathrm{g} / \mathrm{L}$ for carbamates (Figureure 1c). Hormone mimics and chitin inhibitors are one order of magnitude less toxic than the previous chemical groups, with cyromazine in particular being harmless (LC50 $>100 \mathrm{mg} / \mathrm{L}$ ). Insecticides that target the electron transport systems are the least toxic to aquatic insects, with typical LC50 values in the range 1.3-11.5 mg/L. Similar susceptibilities are obtained with the synergist piperonyl butoxide (LC50 $2.7 \mathrm{mg} / \mathrm{L}$ ) and propargite (LC50 $14.8 \mathrm{mg} / \mathrm{L}$ ), while amitraz appears to be almost harmless (LC50 $24.6 \mathrm{mg} / \mathrm{L}$ ).

Fish: Fish show a wide range of sensitivities within the same class of insecticides, but this variability might be due to the variety of species tested. In general, fish are extremely sensitive to pyrethroids (typical 
LC50 0.001-0.13 mg/L), organochlorines (typical LC50 0.02-0.1 mg/L) and respiratory inhibitors (typical LC50 0.01-8.0 mg/L), while amitraz and indoxacarb are also very toxic to them (LC50<1 mg/L). Equally, the acaricides dinactin and pirimidifen appear to be very toxic to fish, with LC50s of 0.003 and $0.09 \mathrm{mg} / \mathrm{L}$ (carp), respectively [18].

Although other neurotoxic insecticides such as cholinesterase inhibitors and dithiols are quite toxic to fish as well, their lethal levels are usually one or two orders of magnitude above that of the former chemical classes (Figure 1d). Fumigants and PCP can be included in the same category (LC50 range 0.17-14.0 $\mathrm{mg} / \mathrm{L}$ ). Hormone mimics and ecdysone agonists have similar levels of toxicity to fish, with $50 \%$ of these compounds having LC50s in the range $0.5-8.4 \mathrm{mg} / \mathrm{L}$. It is apparent in figure $1 \mathrm{c}$ that the toxicity of respiratory inhibitors, OPs and carbamates to fish varies enormously among compounds (and probably among species), even though their geometric mean LC50s are 0.32, 2.5 and 4.9 $\mathrm{mg} / \mathrm{L}$ respectively. Among these, the most toxic compounds to fish (i.e. $\mathrm{LC} 50 \mathrm{~s}<0.1 \mathrm{mg} / \mathrm{L}$ ) are the respiratory inhibitors azocyclotin, propargite, diafenthiuron, rotenone, pyridaben, fenpyroximate, fenazaquin and tebufenpyrad; the OP terbufos, methidathion, mevinphos, chlorethoxyfos, sulfotep, fenamiphos, azinphos-ethyl and azinphosmethyl; and the carbamates carbosulfan and furathiocarb. Equally variable is the toxicity of the three avermectins, ranging widely from the very toxic abamectin (LC50 $0.01 \mathrm{mg} / \mathrm{L}$, trout and bluegill) to the non-toxic emamectin benzoate (LC50 $802 \mathrm{mg} / \mathrm{L}$, trout and minnow).
Synergists are moderately toxic to fish, with typical LC50s in the range 4.2-22 mg/L. Although most IGRs are little or non-toxic to fish, there are a few exceptions: the chitin inhibitor diflubenzuron and the mite growth inhibitor clofentezine have LC50s $<1 \mathrm{mg} / \mathrm{L}$ (zebra fish, trout and bluegill). Interestingly, modern insecticides like neonicotinoids, spinosad and fipronil are practically non-toxic to fish, with LC50s well above $10 \mathrm{mg} / \mathrm{L}$ in all cases.

Amphibians: Toxicological data for this taxon of non-target organisms is growing year after year, prompted by fears that the decline in populations of many species of frogs could be partly due to direct or indirect effects of insecticides [60,61]. The overwhelming majority of toxicity data currently available is for frogs and toads, with only a handful of data being available for salamanders (Ambystoma sp.) Therefore, given the limitations of the dataset, the following remarks should be taken with caution.

As in fish, pyrethroids are by far the most toxic insecticides to amphibians (typical LC50 0.01-0.5 mg/L, Figure 1e), together with the respiratory inhibitors (typical LC50 0.1-0.6 mg/L), pentachlorophenol (LC50 $0.3 \mathrm{mg} / \mathrm{L}$ ) and the acaricide benzoximate (LC50 $0.55 \mathrm{mg} / \mathrm{L}$ ). Apart from these compounds, the cyclodiene endosulfan together with the OPs fenthion, diazinon, chlorpyrifos, malathion, sulfotep and the carbamate thiodicarb are the most toxic insecticides to amphibians (all LC50s $<1 \mathrm{mg} / \mathrm{L}$ ). However, other neurotoxic and respiratory a) earthworms

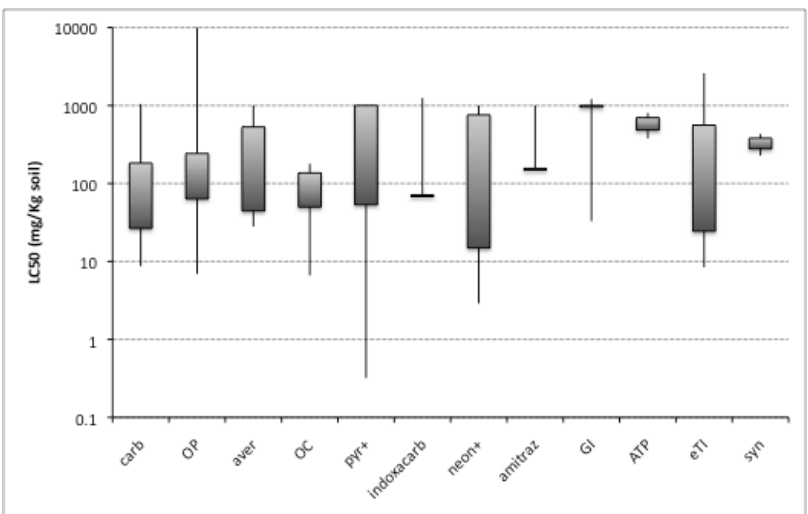

c) birds

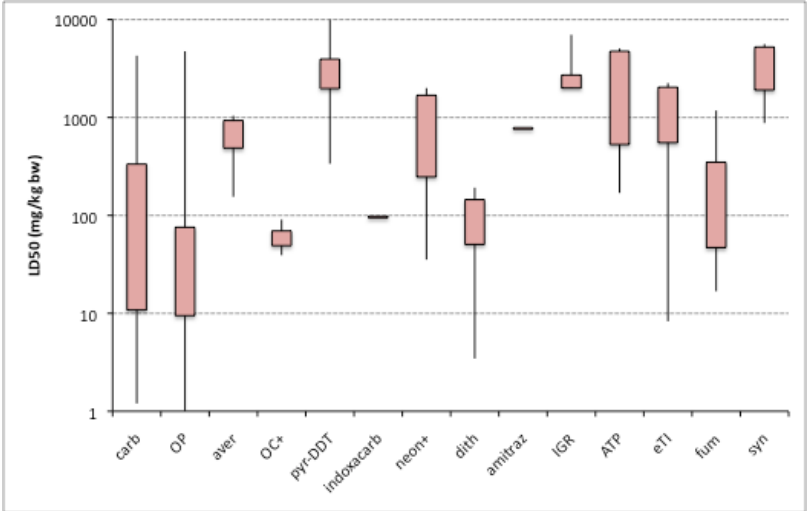

b) honeybees

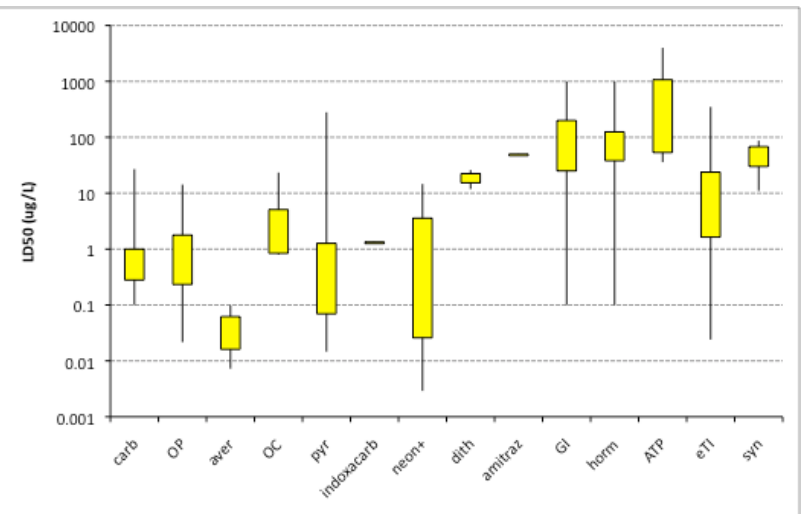

d) mammals

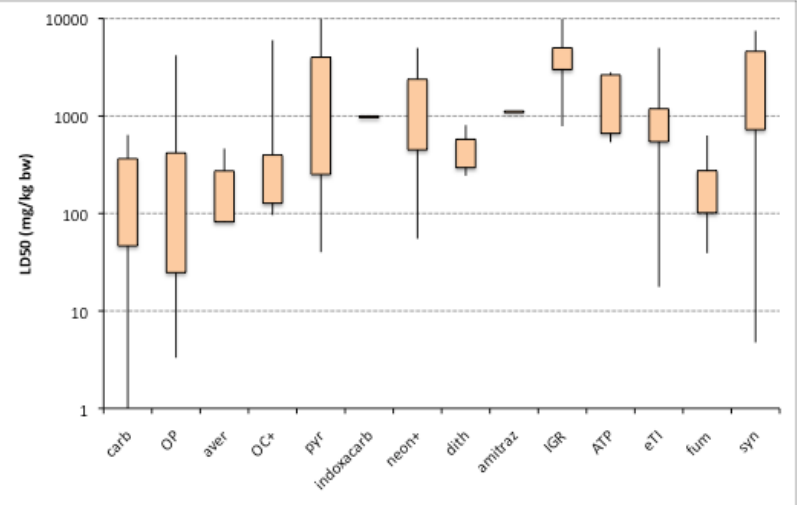

Figure 2: Abbreviations for the insecticide classes: carb = carbamates; OP = organophosphates; aver $=$ avermectins; OC+ = organochlorines + fipronil; pyr+ = pyrethroids + DDT; neon+ = neonicotinoids + spinosad; Chl = chitin inhibitors; GI = growth inhibitors; IGR = insect growth regulators; horm = hormone mimics; dith = dithiols; ATP = ATPase inhibitors; eTI = electron transport inhibitors; fum = fumigants; syn = synergists. 
inhibitors are not as toxic, with typical LC50 values for OC insecticides in the range $0.3-4.0 \mathrm{mg} / \mathrm{L}$, while $50 \%$ of cholinesterase inhibitors have LC50s in the range $2-14 \mathrm{mg} / \mathrm{L}$ (OPs) or $12-39 \mathrm{mg} / \mathrm{L}$ (carbamates), whereas the LC50 of amitraz to frogs is $8.6 \mathrm{mg} / \mathrm{L}$ [62]. Surprisingly, the synergist piperonyl butoxide is quite toxic to amphibians (LC50 $2.1 \mathrm{mg} / \mathrm{L}$, Figure. 1e), suggesting that mechanisms of detoxification in amphibians are more susceptible than those in fish, perhaps because they are more developed.

As in fish, the neonicotinoid imidacloprid is non-toxic to Rana spp. [63]. In general, it can be said that insecticide toxicity levels of most chemical classes to amphibians are similar to those found in fish (Figures $1 \mathrm{~d}$ and 1e).

\section{Terrestrial non-target organisms}

Terrestrial animals have developed efficient detoxification mechanisms in their struggle to counteract the many plant poisons available in nature [58]. As a consequence, they are better prepared to withstand insecticide levels in their bodily tissues. It is not surprising that because of this, together with the fact that most vertebrates are larger in size than invertebrates, many terrestrial animals have a higher tolerance of pesticides (Figure $2 \mathrm{a}-\mathrm{d}$ ).

Earthworms: Fumigants are designed to eliminate nematodes and other soil organisms that may be vectors of diseases. However, toxicity data of these chemicals to earthworms are unavailable (Table 1), even if one may suspect they must be the most toxic pesticides affecting these organisms. Apart from fumigants, all neurotoxic insecticides and respiratory inhibitors of the electron transport system appear to have similar toxicity to earthworms, with LC50s usually in the range 35-130 $\mathrm{mg} / \mathrm{kg}$ of active ingredient in dry soil (Figure 2a). Among them, the most toxic compounds are tefluthrin (LC50 $0.3 \mathrm{mg} / \mathrm{kg}$ ), imidacloprid (3 $\mathrm{mg} / \mathrm{kg}$ ), $\beta$-cyfluthrin (5.5), endosulfan and methidathion (7), chlorfenapyr (8.5) and aldicarb (9).

Fluacrypyrim and PCP are moderately toxic to earthworms, with LC50s of 23 and $77 \mathrm{mg} / \mathrm{kg}$ soil, respectively. Inhibitors of ATPase (e.g. organotins) are only slightly toxic to these organisms (typical LC50 550 $\mathrm{mg} / \mathrm{kg}$ ), as are the synergists (LC50 range $230-450 \mathrm{mg} / \mathrm{kg}$ ) and all the IGRs (typical LC50 980-1000 mg/kg), with the exception of the chitin inhibitor bistrifluron (LC50 $33 \mathrm{mg} / \mathrm{kg}$ ). Interestingly, amitraz and indoxacarb are not toxic to earthworms (LC50 >1000 mg/kg, [18]).

Bees: Being insects, honeybees are very susceptible to all kinds of insecticides. It is worth noting that the most toxic insecticide classes to these non-target insects are the avermectins (LD50 $0.04 \mu \mathrm{g} / \mathrm{bee}$ ), neonicotinoids (typical LD50 0.03-3.6 $\mu \mathrm{g} / \mathrm{bee}$ ) and pyrethroids (typical LD50 0.07-1.3 $\mu \mathrm{g} / \mathrm{bee})$. However, the cyano-substituted neonicotinoids (e.g. thiacloprid and acetamiprid) are three orders of magnitude less toxic to honeybees in spite of having the same mode of action as the other compounds in this class [64]. Cholinesterase inhibitors and OC compounds are also very toxic to these insects, but their typical LD50s are one order of magnitude higher, in the range $0.2-1.8 \mu \mathrm{g} / \mathrm{bee}$ and 0.8-5.1 $\mu \mathrm{g} / \mathrm{bee}$ respectively; toxicity of pirimidifen (LD50 $0.7 \mu \mathrm{g} / \mathrm{bee}$ ) and indoxacarb (LD50 $1.3 \mu \mathrm{g} / \mathrm{bee}$ ) is within the same range. Especially toxic (LD50 $<0.1 \mu \mathrm{g} / \mathrm{bee}$ ) among the $\mathrm{OP}$ and carbamate insecticides are the following compounds: bendiocarb, dicrotophos, diazinon, naled, omethoate, profenofos, pyridaphenthion, isoxathion, chlorethoxyfos and chlorpyrifos.

Dithiols and amitraz are not as toxic to honeybees as other neurotoxic insecticides (Figure $2 \mathrm{~b}$ ). The synergist piperonyl butoxide and PCP are also moderately toxic to bees, with LD50 of 11 and $48 \mu \mathrm{g} /$ bee, respectively. Although some JHs can be very toxic to honeybees (i.e. hydroprene and methoprene), in general these and other IGR compounds are only moderately toxic to Hymenoptera, having LD50s in the range $30-150 \mu \mathrm{g} / \mathrm{bee}$. Respiratory inhibitors of the electron transport system are much more toxic to bees than ATPase inhibitors, with typical LD50s between 1.6-24 $\mu \mathrm{g} /$ bee for the former group and 53$1070 \mu \mathrm{g} / \mathrm{bee}$ for the latter group. Indeed, the ATPase inhibitors are not used to control insects but rather used as acaricides. Stomach poisons and pheromone lures appear not to affect bees, although specific toxicity data for these chemicals are lacking (Table 1).

Birds: Data analysed here are for acute oral toxicity to a range of species based mainly on Mineau et al. [21] and the database sources indicated above. Birds are very sensitive to antagonist neurotoxic compounds such as cholinesterase inhibitors (carbamates and OPs), GABA-R inhibitors (OC and fipronil), nACh-R inhibitors (dithiols), sodium channel blockers (indoxacarb), as well as chlorfenapyr and fumigants [65]. Indeed, among the most toxic insecticides to birds (LD50 $<10 \mathrm{mg} / \mathrm{kg}$ body weight) are the carbamates thiofanox, carbofuran, aldicarb, oxamyl, methiocarb and triazamate; the OPs isocarbophos, fenamiphos, monocrotophos, famphur, dicrotophos, mevinphos, phosphamidon, diazinon, fenthion, parathion, EPN, coumaphos, phorate, ethoprophos, triazophos and terbufos; the dithiol thiocyclam (LD50 $3.5 \mathrm{mg} / \mathrm{kg}$ ), and the electron transport uncoupler chlorfenapyr (LD50 $8.3 \mathrm{mg} / \mathrm{kg}$ ). Fumigants toxicity is typically in the range $47-150 \mathrm{mg} / \mathrm{kg}$ b.w. (Figure $2 \mathrm{c}$ ).

Less toxic to birds are the agonist neurotoxic insecticides of the GABA-R (avermectins), nACh-R (neonicotinoids and spinosad) and particularly those acting upon the sodium channel (pyrethroids and DDT). Thus, the typical LD50 range of the two former agonist groups is $490-930 \mathrm{mg} / \mathrm{kg}$ and $250-1690 \mathrm{mg} / \mathrm{kg}$, respectively. Amitraz and PCP fit also in the same category, whereas pyrethroids are clearly nontoxic to birds (typical LD50 $>2000 \mathrm{mg} / \mathrm{kg}$ ). Apart from chlorfenapyr and DNOC (LD50 $23 \mathrm{mg} / \mathrm{kg}$ ), all other respiratory inhibitors present little hazards to birds (typical LD50 550-2000 mg/kg), especially the ATPase inhibitors, which are practically non-toxic to these animals. Equally, all IGRs, whether inhibitors or hormone mimics, as well as stomach poisons (e.g. toxins of Bacillus thuringiensis) and synergists are innocuous to birds.

Mammals: These data are for acute oral toxicity to mice and rats. Mammals are particularly sensitive to broad-spectrum insecticides such as cholinesterase inhibitors (carbamates and OPs) and agonists and antagonists of the GABA-R like avermectins, fipronil and OCs. Especially toxic (LD50 $<10 \mathrm{mg} / \mathrm{kg}$ body weight) are the following compounds: aldicarb $(0.9 \mathrm{mg} / \mathrm{kg})$, oxamyl (2.8) and thiofanox (8.5) among the carbamates; and chlorethoxyfos (3.3), terbufos (3.5) phorate (3.8), tebupirimfos (5.5), disulfoton (6.6), chlormephos (7.0), fenamiphos and parathion (8.0), mevinphos and sulfotep (10) among the OPs. Avermectins have typical LD50s in the range $80-250 \mathrm{mg} / \mathrm{kg}$, whereas OCs are typically between $130-400 \mathrm{mg} / \mathrm{kg}$; the LD50 of fipronil is $96 \mathrm{mg} / \mathrm{kg}$. Fumigants and PCP are also very toxic to mammals, in particular phosphine $(40 \mathrm{mg} / \mathrm{kg})$, but their typical LD50s are in the range $100-275 \mathrm{mg} / \mathrm{kg}$.

All other neurotoxic insecticides are only moderately toxic to mammals, from dithiols (LD50 $408 \mathrm{mg} / \mathrm{kg}$ ) to amitraz (LD50 1125 $\mathrm{mg} / \mathrm{kg}$ ) and pyrethroids (typical LD50 250-4000 mg/kg). Respiratory inhibitors can be equally toxic (typical LD50 550-1200 mg/kg), and hydrogen cyanide (LD50 $18 \mathrm{mg} / \mathrm{kg}$ ) and DNOC (LD50 $68 \mathrm{mg} / \mathrm{kg}$ ) are particularly toxic.

Finally, acaricide ATPase inhibitors, the majority of synergists, 
stomach poisons and all IGR compounds are quite harmless to mammals (Figure 2d).

\section{Conclusions}

It appears that the mode of action of insecticides is responsible for their higher or lower toxicity to non-target organisms. However, the large variations in susceptibility among different animal taxa suggest that certain biochemical traits particular to a group of organisms are responsible for a specific level of sensitivity. Aquatic arthropods are most susceptible to all types of insecticides because they share many physiological features with the target insects. Other aquatic organisms, such as fish and amphibians, are very sensitive to broad-spectrum neurotoxic and respiratory inhibitor insecticides, but not so much to selective insecticides such as IGRs and stomach poisons. Terrestrial vertebrates are also sensitive to most neurotoxicants and respiratory inhibitors, with the exception of those insecticides derived from natural toxins produced by plants or fungi (e.g. pyrethroids, neonicotinoids, avermectins, spinosad), which appear to have little or no toxicity in birds and mammals.

It is no coincidence that natural insecticides such as pyrethrum or nicotine, and their corresponding man-made derivatives, are less toxic to terrestrial animals than other neurotoxic substances such as OC, OP and carbamate insecticides. Firstly, the mode of action of the natural insecticides on their target receptor is typically agonistic, whereas that of the man-made products is more often antagonistic. Secondly, birds and mammals have evolved in environments where poisonous plants grow, producing seeds and fruits that may form part of the diet of those animals. Consequently, they have evolved and altered their neurophysiological mechanisms to cope with the possible threat of poisoning. By the same token, it is not surprising that the most toxic substances to organisms are the artificial, man-made insecticides, for which most organisms have been unable to evolve the corresponding physiological traits that may counteract their effect.

\section{References}

1. Sánchez-Bayo F, van den Brink PJ, Mann RM, editors. (2011) Ecological Impacts of Toxic Chemicals. Bentham Science Publishers Ltd. Online, 281 p.

2. Guruge KS, Tanabe S (2001) Contamination by persistent organochlorines and butyltin compounds in the west coast of Sri Lanka. Mar Pollut Bull 42: 179-186.

3. Sánchez-Bayo $F$ (2011) Impacts of agricultural pesticides on terrestria ecosystems. In: Sánchez-Bayo, F, van den Brink, PJ, Mann, R (eds.) Ecological Impacts of Toxic Chemicals. Bentham Science Publishers, Online, pp. 63-87

4. Reinecke S, Reinecke A (2007) The impact of organophosphate pesticides in orchards on earthworms in the Western Cape, South Africa. Ecotoxicol Environ Saf 66: 244-251.

5. Liang W, Beattie G, C. A, Meats A, Spooner-Hart R (2007) Impact on soildwelling arthropods in citrus orchards of spraying horticultural mineral oil, carbaryl or methidathion. Aust J Entomol 46: 79-85.

6. Sánchez-Bayo F, Yamashita H, Osaka R, Yoneda M, Goka K (2007) Ecological effects of imidacloprid on arthropod communities in and around a vegetable crop. J Environ Sci Health B 42: 279-286.

7. Hart J, Milsom T, Fisher G, Wilkins V, Moreby S, et al. (2006) The relationship between yellowhammer breeding performance, arthropod abundance and insecticide applications on arable farmland. J Appl Ecol 43: 81-91.

8. Mineau P (2002) Estimating the probability of bird mortality from pesticides sprays on the basis of the field study record. Environ Toxicol Chem 21: 14971506.

9. Beketov M, Schafer RB, Marwitz A, Paschke A, Liess M (2008) Longterm stream invertebrate community alterations induced by the insecticide thiacloprid: effect concentrations and recovery dynamics. Sci Total Environ 405: 96-108.
10. Schäfer RB, van den Brink PJ, Liess M (2011) Impacts of pesticides on freshwater ecosystems. In: Sánchez-Bayo, F, van den Brink, PJ, Mann, R (eds.) Ecological Impacts of Toxic Chemicals. Bentham Science Publishers, Online, pp. 111-137.

11. Webber NR, Boone MD, Distel CA (2010) Effects of aquatic and terrestrial carbaryl exposure on feeding ability, growth, and survival of American toads. Environ Toxicol Chem 29: 2323-2327.

12. Hayasaka D, Korenaga T, Sánchez-Bayo F, Goka K (2012) Differences in ecological impacts of systemic insecticides with different physicochemical properties on biocenosis of experimental paddy fields. Ecotoxicology 21:191201.

13. Konradsen F, van der Hoek W, Cole DC, Hutchinson G, Daisley H, et al. (2003) Reducing acute poisoning in developing countries--options for restricting the availability of pesticides. Toxicology 192: 249-261.

14. Cataño HC, Carranza E, Huamaní C, Hernández AF (2008) Plasma cholinesterase levels and health symptoms in Peruvian farm workers exposed to organophosphate pesticides. Arch Environ Contam Toxicol 55: 153-159.

15. Matsumura F (1985) Toxicology of Pesticides, Plenum Press, New York.

16. Theiling KM, Croft BA (1988) Pesticide side-effects on arthropod natural enemies: a database summary. Agric Ecosyst Environ 21: 191-218.

17. Desneux N, Decourtye A, Delpuech J-M (2007) The sublethal effects of pesticides on beneficial arthropods. Annu Rev Entomol 52: 81-106.

18. Tomlin CDS (2009) Editor, editor.^editors. The e-Pesticide Manual. 12 ed. City: British Crop Protection Councilof.

19. Wu Y, Lin C, Yuan $L$ (2007) Characteristics of six cladocerans in relation to ecotoxicity testing. Ecol Indicators 7: 768-775.

20. Calleja MC, Persoone G, Geladi P (1994) Comparative acute toxicity of the first 50 multicentre evaluation of in vitro cytotoxicity chemicals to aquatic nonvertebrates. Arch Environ Contam Toxicol 26: 69-78.

21. Mineau P, Baril A, Collins BT, Duffe J, Joerman G, et al. (2001) Pesticide acute toxicity reference values for birds. Rev Environ Contam Toxicol 170: 13-74.

22. Sánchez-Bayo $F(2006)$ Comparative acute toxicity of organic pollutants and reference values for crustaceans. I. Branchiopoda, Copepoda and Ostracoda. Environ Pollut 139: 385-420.

23. Driver C, Ligotke M, Van Voris P, McVeety B, Greenspan B, et al. (1991) Routes of uptake and their relative contribution to the toxicologic response of northern bobwhite (Colinus virginianus) to an organophosphate pesticide. Environ Toxicol Chem 10: 21-33.

24. Luo $Y$, Zang $Y$, Zhong $Y$, Kong Z (1999) Toxicological study of two novel pesticides on earthworm Eisenia foetida. Chemosphere 39: 2347-2356.

25. Rohr JR, Raffel TR, Sessions SK, Hudson PJ (2008) Understanding the net effects of pesticides on amphibian trematode infections. Ecol Appl 18: 1743 1753.

26. Manning T (2005) Endocrine disrupting chemicals - A review of the state of the science. Australas J Ecotoxicol 11: 1-52.

27. Blus LJ, Gish CD, Belisle AA, Prouty RM (1972) Logarithmic relationship of DDE residues to eggshell thinning. Nature 235: 376-377.

28. Cooke AS (1973) Shell thinning in avian eggs by environmental pollutants Environ Pollut 4: 85-152.

29. Ratcliffe DA (1967) Decrease in eggshell weight in certain birds of prey. Nature 215: 208-210.

30. Peakall DB (1993) DDE-induced eggshell thinning: an environmental detective story. Environ Rev 1: 13-20.

31. Cox RL, Wilson WT (1984) Effects of permethrin on the behavior of individually tagged honey bees, Apis mellifera L. (Hymenoptera: Apidae). Environ Entomo 13: $375-378$

32. Relyea Rick A (2004) Synergistic impacts of malathion and predatory stress on six species of North American tadpoles. Environ Toxicol Chem 23: 1080-1084.

33. Grue CE, Powell GVN, McChesney MJ (1982) Care of nestlings by wild female starlings exposed to an organophosphate pesticide. J Appl Ecol 19: 327-335.

34. Cole LM, Nicholson RA, Casida JE (1993) Action of phenylpyrazole insecticides at the GABA-gated chloride channel. Pestic Biochem Physiol 46: 47-54. 
Citation: Sánchez-Bayo F (2012) Insecticides Mode of Action in Relation to Their Toxicity to Non-Target Organisms. J Environment Analytic Toxicol S4:002. doi:10.4172/2161-0525.S4-002

35. Abalis IM, Eldefrawi ME, Eldefrawi AT (1985) High-affinity stereospecific binding of cyclodiene insecticides and gamma BHC to gamma aminobutyricacid receptors of rat brain. Pestic Biochem Physiol 24: 95-102.

36. Gant DB, Chalmers AE, Wolff MA, Hoffman HB, Bushey DF (1998) Fipronil: action at the GABA receptor. In: Kuhr, RJ, Motoyama, N (eds.) Pesticides and the Future, vol. 2. IOS Press, Amsterdam, pp. 133-146.

37. Hertlein MB, Mavrotas C, Jousseaume C, Lysandrou M, Thompson GD, et al. (2010) A review of spinosad as a natural product for larval mosquito control. J Am Mosq Control Assoc 26: 67-87.

38. Matsuda K, Buckingham SD, Kleier D, Rauh JJ, Grauso M, et al. (2001) Neonicotinoids: insecticides acting on insect nicotinic acetylcholine receptors. Trends Pharmacol Sci 22: 573-580.

39. Tomizawa M, Casida JE (2003) Selective toxicity of neonicotinoids attributable to specificity of insect and mammalian nicotinic receptors. Annu Rev Entomol 48: 339-364.

40. Sánchez-Bayo F, Goka K (2006) Influence of light in acute toxicity bioassays of imidacloprid and zinc pyrithione to zooplankton crustaceans Aquat Toxicol 78: 262-271

41. Casida JE, Quistad GB (2004) Why insecticides are more toxic to insects than people: the unique toxicology of insects. J Pestic Sci 29: 81-86.

42. Guerrero J (2009) Canine flea and tick control: a reference guide to EPAapproved spot-on products. Canine flea and tick control: a reference guide to EPA-approved spot-on products: $35 \mathrm{pp}$.

43. Walker CH, Hopkin SP, Sibly RM, Peakall DB (2001) Principles of Ecotoxicology. (2nd) ed, Taylor \& Francis, Glasgow, UK.

44. Albers PH, Klein PN, Green DE, Melancon MJ, Bradley BP, et al. (2006) Chlorfenapyr and mallard ducks: overview, study design, macroscopic effects, and analytical chemistry. Environ Toxicol Chem 25: 438-445.

45. Wambeke Ev (1992) Effects and fate of soil fumigants in the soil, atmospheric and aquatic environment. Parasitica 48: 43-50.

46. Bluemel S, Stolz M (1993) Investigations on the effect of insect growth regulators and inhibitors on the predatory mite Phytoseiulus persimilis A.H. with particular emphasis on cyromazine. Zeitschrift fuer Pflanzenkrankheiten und Pflanzenschutz 100: 150-154.

47. Brock TCM, Roessink I, Belgers JDM, Bransen F, Maund SJ (2009) Impact of a benzoyl urea insecticide on aquatic macroinvertebrates in ditch mesocosms with and without non-sprayed sections. Environ Toxicol Chem 28: 2191-2205.

48. Liber K, Schmude KL, Corry TD (1996) Effects of the insect growth regulator diflubenzuron on insect emergence within littoral enclosures. Environ Entomo 25: $17-24$.

49. Dhadialla TS, Carlson GR, Le DP (1998) New insecticides with ecdysteroida and juvenile hormone activity. Annu Rev Entomol 43: 545-569.
50. Dinan L, Savchenko T, Whiting P, Sarker SD (1999) Plant natural products as insect steroid receptor agonists and antagonists. Pestic Sci 55: 331-335.

51. Ishaaya I, Horowitz AR (1995) Pyriproxyfen, a novel insect growth regulator for controlling whiteflies: Mechanisms and resistance management. Pestic Sci 43: $227-232$

52. Chu KH, Wong CK, Chiu KC (1997) Effects of the insect growth regulator (S) methoprene on survival and reproduction of the freshwater cladoceran Moina macrocopa. Environ Pollut 96: 173-178.

53. Schnepf E, Crickmore N, Van Rie J, Lereclus D, Baum J, et al. (1998) Bacillus thuringiensis and its pesticidal crystal proteins. Microbiol Mol Biol Rev 62: 775 806

54. Mordue AJ, Simmonds MSJ, Ley SV, Blaney WM, Mordue W, et al. (1998) Actions of azadirachtin, a plant allelochemical, against insects. Pestic Sci 54 277-284.

55. Walker MK, Stufkens MAW, Wallace AR (2007) Indirect non-target effects of insecticides on Tasmanian brown lacewing (Micromus tasmaniae) from feeding on lettuce aphid (Nasonovia ribisnigri). Biol Control 43: 31-40.

56. Conney AH, Chang R, Levin WM, Garbut A, Munro-Faure AD, et al. (1972) Effects of piperonyl butoxide on drug metabolism in rodents and man. Arch Environ Health 24: 97-106

57. Witzgall P, Kirsch P, Cork A (2010) Sex pheromones and their impact on pest management. J Chem Ecol 36: 80-100.

58. Walker CH (2001) Organic Pollutants, Taylor \& Francis, Glasgow, UK.

59. Slabbert JL, Venter EA (1999) Biological assays for aquatic toxicity testing Water Sci Technol 39: 367-373.

60. Bridges CM, Semlitsch RD (2000) Variation in pesticide tolerance of tadpoles among and within species of Ranidae and patterns of amphibian decline. Conserv Biol 14: 1490-1499.

61. Sparling DW, Fellers GM (2009) Toxicity of two insecticides to California, USA anurans and its relevance to declining amphibian populations. Environ Toxico Chem 28: 1696-1703.

62. Osano O, Oladimeji AA, Kraak MHS, Admiraal W (2002) Teratogenic effects of amitraz, 2,4-Dimethylaniline, and paraquat on developing frog (Xenopus) embryos. Arch Environ Contam Toxicol 43: 42-49.

63. Feng S, Kong Z, Wang X, Zhao L, Peng P (2004) Acute toxicity and genotoxicity of two novel pesticides on amphibian, Rana N. Hallowell. Chemosphere 56 : 457-463.

64. Iwasa T, Motoyama N, Ambrose JT, Roe RM (2004) Mechanism for the differential toxicity of neonicotinoid insecticides in the honey bee, Apis mellifera. Crop Protection 23: 371-378

65. Walker $\mathrm{CH}$ (2003) Neurotoxic pesticides and behavioural effects upon birds Ecotoxicology 12: 307-316. 